\title{
Study of the clinical and histopathological repercussions of the "omental band" in dogs' stomach"
}

\author{
Sávio Lana Siqueira ${ }^{\mathrm{I}}$, Adriana Torres da Silva ${ }^{\text {II }}$, Cléber Stockler Ribeiro Bráulio ${ }^{\mathrm{III}}$, Marina Paranhos Jalles ${ }^{\mathrm{IV}}$, Guilherme Matos \\ Serretti Mendes ${ }^{\mathrm{IV}}$, Pedro Sérgio Cascimiro Nicolau do Carmo ${ }^{\mathrm{IV}}$, Maria Luiza Lopes Camargos ${ }^{\mathrm{IV}}$
}

DOI: http://dx.doi.org/10.1590/S0102-865020150020000010

${ }^{\mathrm{I}} \mathrm{MsC}, \mathrm{PhD}$, Associate Professor, Human Anatomy, Faculty of Medical Sciences of Minas Gerais (FCMMG), Belo Horizonte-MG. Associate Professor of Surgery, Federal University of Ouro Preto (UFOP), Brazil. Conception, design, intellectual and scientific content of the study; critical revision; final approval of the version to be published.

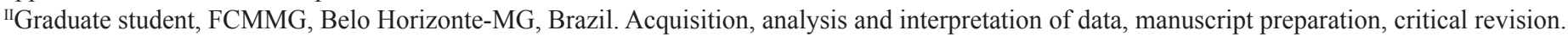

IIIMD, FCMMG, Belo Horizonte-MG, Brazil. Acquisition of data.

${ }^{\text {IV }}$ Graduate student, FCMMG, Belo Horizonte-MG, Brazil. Scientific and intellectual content of the study.

\section{ABSTRACT}

PURPOSE: To evaluate the efficacy of the "omental band" as a bariatric surgical technique.

METHODS: A sample of 35 dogs was studied. The Test Group was composed by $20 \mathrm{dogs}$. Of these, six were observed by 10 days, six were observed by 20 days and eight were observed by 30 days of post-operatory. The Control Group was composed by 15 dogs. Of these, five were observed by 10 days, five were observed by 20 days and five were observed by 30 days of post-operatory. The weight loose was the variable utilized to the evaluation of the efficacy of the surgical technique described in this study, once all of the dogs were weighted in precision balance before the surgical act and at the end of the post-operatory observation period.

RESULTS: At the end of the study it was observed that the weight loose of the dogs submitted to the "omental band's" surgical technique was meaningfully higher in comparison with the dogs of the Control Group at the end of the post-operatory observation period.

CONCLUSION: The surgical technique of the "omental band" showed effective in dogs, once has proposed a meaningfully weight loose.

Key words: Bariatric Surgery. Obesity. Pyloric Antrum. Omentum. Dogs. 


\section{Introduction}

The obesity is one of the most worrying public health's problem in the actuality, because of its increasing grow and of its grave consequences that increase the mortality and the morbidity. It's a result of the inadequate feed and of the sedentary comportment between other factors involving genetic, comportment, psychological, social, metabolic and endocrine components ${ }^{1,2}$.

The obesity can be objectively classified utilizing the Mass Corporeal Indices (IMC). It's considerate a person of normal weigh that one with the IMC between 19 and $24,9 \mathrm{~kg} / \mathrm{m}^{2}$. That ones with IMC between 25 and 30 are considerate with overweigh, that ones with IMC between 30 and 40 are classified like obese, while people with IMC upper than 40 are portable of morbid obesity $^{1,2}$

Patients with morbid obesity require one efficient approach to promote loose of weight, once that is a condition that put in risk the life of the patient whereas turns worse its quality of life and self-worth ${ }^{1}$. Today, the bariatric surgery is an option to people with morbid obesity that come showing efficient results with effective loose of weight. ${ }^{2}$

The conservatory treatments like dietetic therapy and physical exercises are not showing efficacy in the maintenance of the weigh's loose in morbid obese ${ }^{2}$. To indicate a person to the bariatric surgery, it has to fill criteria, like IMC bigger than $40 \mathrm{~kg} /$ $\mathrm{m}^{2}$ or higher than $35 \mathrm{mg} / \mathrm{kg}^{2}$ in association with diseases with, in the minimum, five years of evolution and that can be controlled with the weight's loose, like: diabetes, arterial hypertension, osteoarticular diseases, sleep's apnea or absence of endocrine diseases as causes of the obesity and historic of fail with the utilization of conservatory treatments ${ }^{1}$.

The ant obesity surgeries can be divided in restrictive procedures (that limit the gastric capacity), bad absorptive (that interfere in the digestion) and one combination of both techniques ${ }^{1}$. In this way, the bariatric surgery constitutes a mix technique that rests the size of the gastric cavity (and, consequently, the quantity of ingested aliments) and reduces the intestinal surface in contact with the aliment (dysabsorption.). The principal kind of bariatric surgery in the actuality is the gastric bypass in Roux $\mathrm{Y}^{3}$.

The surgical techniques utilized to correct the problem of the obesity, beside of efficient, present lots of collateral effects that can cause complications. Thus, is necessary the continuous research to develop surgical techniques that proportion the smaller possible number of post-operatory disturbances and, at the same time, possibility a meaningfully and lasting weight's loose.
The importance of the surgical technique with the confection of the "omental band" in dogs' stomach (described in this study) consists to restring the gastric amplitude with consequently loose of gastric reserve without the utilization of exogenous materials. These alterations culminate with the animal's loss of weight and, in case of the technique shows effective, the human's loss of weigh.

The proposed surgery, beside to be conceptually simple, represents an innovation on the camp of the bariatric surgery, as there are no relates in the literature of similar techniques. This study has as an objective to evaluate the efficacy of the "omental band" in dog's stomach as a bariatric surgical technique.

\section{Methods}

This study was approved by the Ethics Committee on Animal Research according to the legislation in force, Federal Law number 11.794 of October $8^{\text {th }}, 2008$ and the decree number 6.689 of July $15^{\text {th }}, 2009$.

\section{Experimental animals}

It was utilized 35 mongrel dogs, 24 male and 11 female, of middle port. The Control Group was formed by 15 dogs that were submitted just to a median laparotomy and divided posteriorly in 3 subgroups of 5 dogs each one, constituting the Control Group 1 (4 male and 1 female) observed by 10 days, the Control Group 2 (2 male and 3 female) observed by 20 days and the Control Group 3 (4 male and 1 female) observed by 30 days.

The other 20 animals were operated, constituting the Test Group in that one the dogs were submitted to the surgical technique described in this study and separate in 3 groups: 2 groups of 6 and 1 group of 8 dogs. The Test Group 1 (4 male and 2 female) were submitted to a post-operatory observation period of 10 days; the Test Group 2 (6 male dogs), to a postoperatory observation period of 20 days and the Test Group 3 ( 4 male and 4 female) to a post-operatory observation period of 30 days.

\section{Pre-operatory and anesthesia}

The dogs utilized were prepared in the 24 hours that antecede the operation, being submitted to a bath with neutron soap and done the conditioning of the dogs in individual stalls. All of the animals were already previously vaccinated and were also weighted in precision balance. 
After the contention of each dog, it was catheterized the cephalic vein of its upper left limb with dispositive of venous puncture $19 \mathrm{G}$, proceeding to the infusion of saline solution $0,9 \%$ to 20 drops/minute, and the infusion of Thiopental ${ }^{\circledR}$ in the dose of $20 \mathrm{mg} / \mathrm{kg}$ of weight to the sedation.

Each dog was positioned in dorsal decubiti in the specific operatory table with immobilization of hogties, cervical hyperextension and lateral rotation of the head, with administration of the oxygen therapy by nasal catheter to 2 liters by minute. It was then proceed to the abdominal tricotomy, after routine abdominal palpation and realized the anti-sepsis with solution of PVP-I on the abdomen, extern genitally and thighs. It was done the infusion of Ketamine Hydrochloride ${ }^{\circledR}, 5 \mathrm{mg} / \mathrm{kg}$ of weigh, in the vein.

\section{Surgical technique}

In the animals of the Test Groups 1,2 and 3 it were done an operatory incision in the anterior abdominal wall of approximately 7 centimeters upper umbilical in the alba line and open by plans of the skin and subcutaneous tissue with posterior longitudinal section of the parietal peritoneum with the open of the peritoneal cavity. In the cases that was necessary it was done the hemostasis with electro cauterization of the vessels. It was done the manual explosion of the stomach lightened in the superior direction of the plan of the incision, to the exterior of the abdominal cavity; liberation of the major omentum of its insertion of the transverse colon pediculating it with its vascularization, being this maintained by the left side (Figure 1). I was done a rhombus division of the minor omentum, with a curve hemostatic pincer (Figure 1).

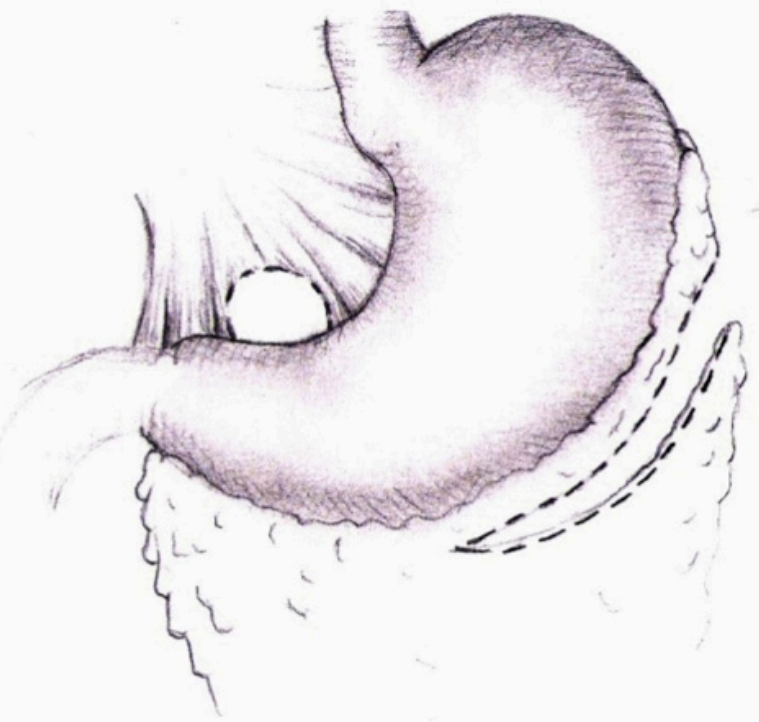

FIGURE 1 - Liberation of the major omentum and open in the minor omentum
Pass of the free extremity of the pediculate major omentum by the open of the minor omentum, involving the gastric antrum by two ways (Figure 2). Fixation of the "omental band" to the gastric wall by seromuscular separated points, with thread of polyamide 2.0 (Figure 3 ). In the cases that occurred complications in the trans operatory, it were done maids with the finality to preserve the integrity of the animal and save it of any suffer.

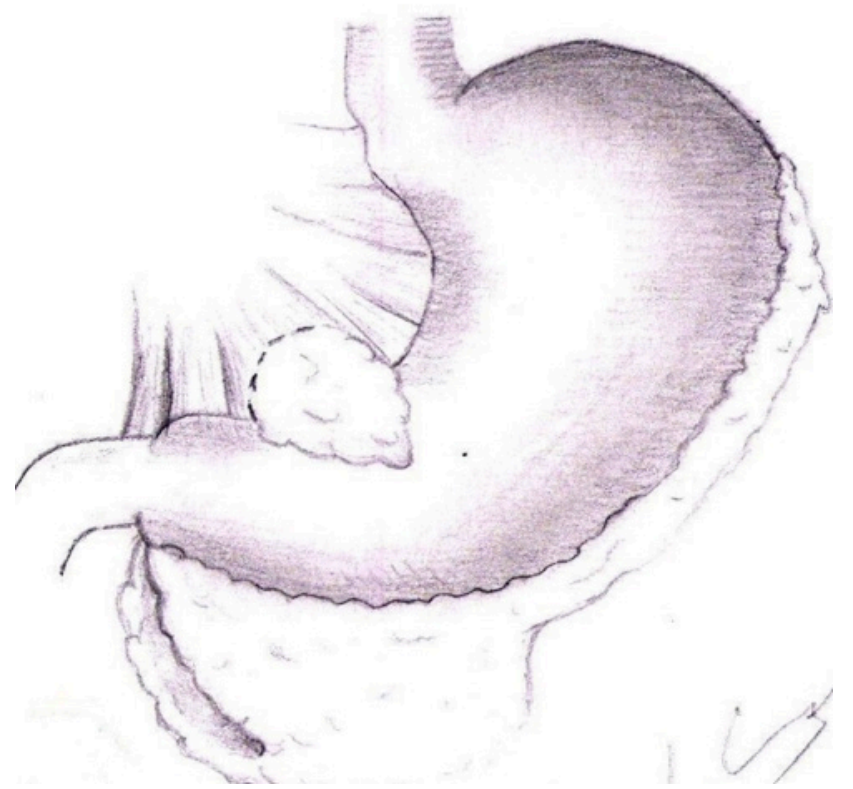

FIGURE 2 - Pass of the major pediculate omentum by the open made in the minor omentum by two ways, involving the gastric antrum.

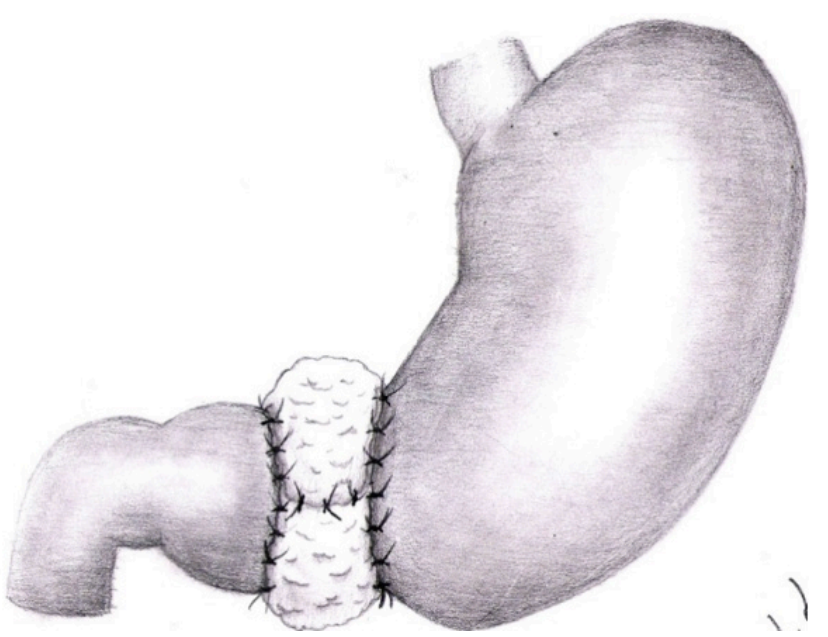

FIGURE 3 - Final aspect of the "omental band" after to be sutured to the gastric antrum.

After systematic review of the peritonea cavity, it was done the wall's close with continuous suture of the parietal peritonea and alba line with thread of polyamide 2.0. The subcutaneous was approximate with simple suture with thread of catgut 2.0 and the skin with simple points of polyamide 4.0 . 
In the animals of the Control Groups 1, 2 and 3 it was done just the operatory incision in the anterior abdominal wall upper umbilical and open by plans of skin, subcutaneous and alba line, with posterior longitudinal section of the parietal peritoneum with open of the peritoneal cavity and wall's close with continuous suture of the parietal peritoneum and alba line with thread of polyamide 2.0, followed by the synthesis of the subcutaneous tissue with suture done with thread of catgut 2.0 and of the skin with simple points done with thread of polyamide 4.0.

\section{Clinical control of the dogs in the post-operatory period}

All of the dogs were accompanied and evaluate diary, being observed the date of the beginning of the spontaneous ingestion of water and food, clinical exam of thorax and abdomen with palpation and auscultate and exam of the operatory abdominal hurt. In the first four days of post-operatory period, it was administrate, in all of the dogs, Dipyrone Sodium ${ }^{\circledR}$ (500 mg/ $\mathrm{ml}$ ), by the parenteral intramuscular via, $1.000 \mathrm{mg}$, of 12 in 12 hours to analgesia.

\section{Analysis of the clinical repercussions}

The dogs were weight in precision balance before the operatory act and at the final of the observation period of each respective Test Group and Control Group (10 days to the Group 1, 20 days to the Group 2 and 30 days to the Group 3). The results were then submitted to statistical analysis, utilizing the weight loose as the principal clinical parameter to the evaluation of the efficacy of the surgical technique described in this study.

\section{Statistical analysis}

The statistical test utilized by the evaluation of the studied variable (weight loose) in the Test and Control Groups was the Student's T Test, with a significance level $p<0,05$.

\section{Necropsies}

The dogs that died because of complications were necropsied in the same day, by median laparotomy upper umbilical, to identify the associate alterations and the cause of the obit. The other dogs were necropsied after the post-operatory observation period. It was done, also: other median laparotomy upper umbilical, identification of the region where was made the "omental band", put all the stomach out, longitudinal open of it, with continuous incision in its ventral face, empty and wash of the mucosa with current water. It was necropsied, also, the 15 dogs of the Control Group after the observation periods.

\section{Histopathological analysis}

After the animals' euthanasia, it was done the put out of two segments of the stomach of one of the dogs of the Test Group 2, with post-operatory observation period of 20 days. Each segment was put in a plastic box, labeled and separated, with formaldehyde solution at $10 \%$ and submitted posteriorly to histopathological analysis. The animal has an initial weight of $9000 \mathrm{~g}$ and, at the end of the observation period it was observed the loose of $1800 \mathrm{~g}, 20 \%$ of the weight of the pre-operatory. One of the laminas was made by a cut of the body's stomach, proximal to the "omental band", and the other of the antrum, segment over that it was made the "omental band".

\section{Results}

\section{Ponderal loose}

\section{Test Group 1}

The Test Group 1 was constituted by six animals (four male and two female) and had its post-operatory observation period of 10 days. We're going to present the initial weight and the final weight of each animal after 10 days at post-operatory of the date of realization of the "omental band's" surgical technique (Table 1).

TABLE 1 - Evaluation of the weight loose of the Test Group 1 (observation by 10 days of post-operatory period).

\begin{tabular}{lccc}
\hline Dog & Sex & $\begin{array}{c}\text { Initial weight } \\
\text { (in grams) }\end{array}$ & $\begin{array}{c}\text { Final weight } \\
\text { (in grams) }\end{array}$ \\
\hline 1 & Female & 2300 & 2000 \\
2 & Male & 5000 & 4500 \\
3 & Female & 6300 & 6000 \\
4 & Male & 7200 & 7000 \\
5 & Male & 8300 & 8100 \\
6 & Male & 5300 & 5000 \\
Average+ PatternDetour & - & $5733+$ & $4683+2$ \\
& & 1896.2 & 086.1 \\
\hline
\end{tabular}

The statistical analysis was done throughout the application of Student's T Test, to evaluate if the weight loose of the animals were meaningful at the end of the post-operatory observation period. The Control Group 1, constituted by five animals (four male and one female), also with post-operatory 
observation period of 10 days, was utilized like a parameter to comparison in the statistical analysis (Figure 4).

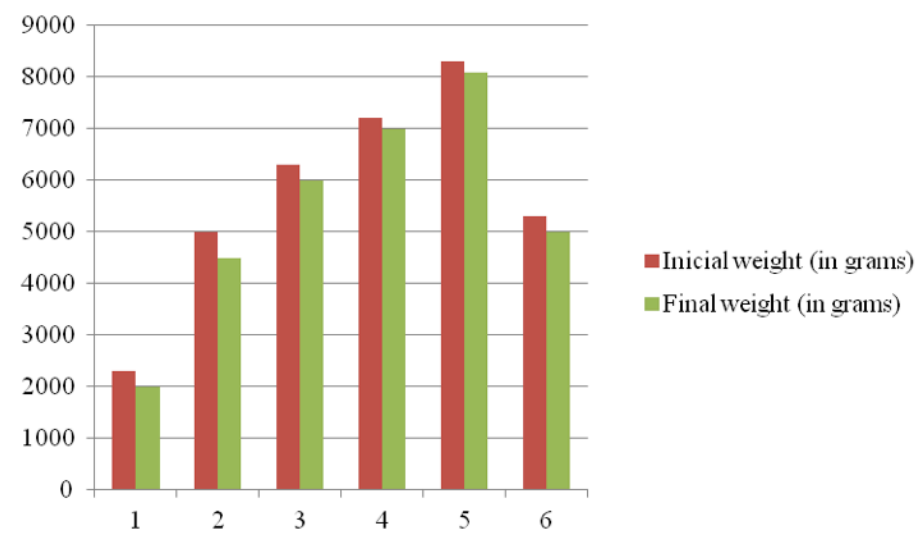

FIGURE 4 - Evaluation of the weight loose of the Test Group 1 (observation by 10 days of post-operatory period).

Observing the value of the table of the Student's T Test, we can see that the $t_{0}$ of 6.64 is bigger than the $t_{c}$ of 2.26 (found value in the table with $\mathrm{p}<0.05$ and nine degrees of liberty). Didn't exist meaningfully loose of weigh in the correspondent control group. Then, we conclude that the weight loose in the dogs submitted to the surgical technique of the "omental band" and of the group of dogs not submitted to the same technique is different and, then, we avert the null hypothesis $\left(\mathrm{H}_{0}\right)$ that affirms that there aren't differences between the weight loose of the two groups, accepting the alternative hypothesis $\left(\mathrm{H}_{1}\right)$, that affirms that the weight loose is meaningfully bigger in the group of dogs submitted to the technique of the "omental band".

\section{Test Group 2}

The Test Group 2 was constituted by six animals (all male) and had its post-operatory observation period of 20 days. We're going to present the initial weight and the final weight of each animal after 20 days at post-operatory of the date of realization of the "omental band's" surgical technique (Table 2).

TABLE 2 - Evaluation of the weight loose of the Test Group 2 (observation by 20 days of post-operatory period).

\begin{tabular}{lccc}
\hline Dog & Sex & $\begin{array}{c}\text { Initialweight } \\
\text { (in grams) }\end{array}$ & $\begin{array}{c}\text { Final weight } \\
\text { (in grams) }\end{array}$ \\
\hline 1 & Male & 6300 & 4500 \\
2 & Male & 9000 & 7200 \\
3 & Male & 5200 & 4000 \\
4 & Male & 5100 & 4000 \\
5 & Male & 4300 & 3700 \\
6 & Male & 5200 & 4100 \\
Average+ & - & $5850 \pm 1591.8$ & $4583,3 \pm 1193.6$ \\
PatternDetour & & & \\
\hline
\end{tabular}

The statistical analysis was done throughout the application of Student's T Test, to evaluate if the weight loose of the animals were meaningful at the end of the post-operatory observation period. The Control Group 2, constituted by five animals (two male and three female), also with post-operatory observation period of 20 days, was utilized like a parameter to comparison in the statistical analysis (Figure 5).

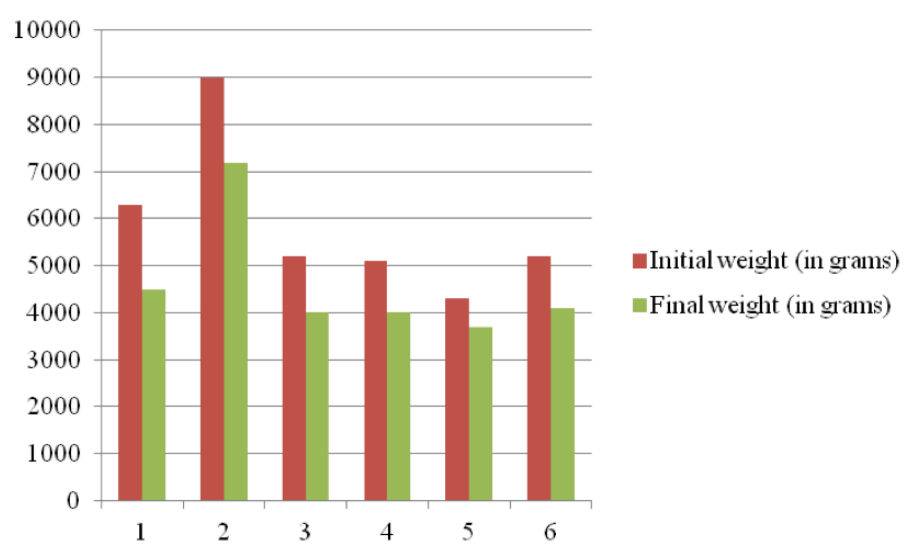

FIGURE 5 - Evaluation of the weight loose of the Test Group 2 (observation by 20 days of post-operatory period).

Observing the value of the table of the Student's T Test, we can see that the $t_{0}$ of 6.64 is bigger than the $t_{c}$ of 2.26 (found value in the table with $\mathrm{p}<0.05$ and nine degrees of liberty). Didn't exist meaningfully loose of weigh in the correspondent control group. Then, we conclude that the weight loose in the dogs submitted to the surgical technique of the "omental band" and of the group of dogs not submitted to the same technique is different and, then, we avert the null hypothesis $\left(\mathrm{H}_{0}\right)$ that affirms that there aren't differences between the weight loose of the two groups, accepting the alternative hypothesis $\left(\mathrm{H}_{1}\right)$, that affirms that the weight loose is meaningfully bigger in the group of dogs submitted to the technique of the "omental band".

\section{Test Group 3}

The Test Group 3 was constituted by 8 animals ( 4 male and 4 female) and had its post-operatory observation period of 30 days. We're going to present the initial weight and the final weight of each animal after 30 days at post-operatory of the date of realization of the "omental band's" surgical technique (Table 3). 
TABLE 3 - Evaluation of the weight loose of the Test Group 3 (observation by 30 days of post-operatory period).

\begin{tabular}{lccc}
\hline Dog & Sex & $\begin{array}{c}\text { Initialweight } \\
\text { (in grams) }\end{array}$ & $\begin{array}{c}\text { Final weight } \\
\text { (in grams) }\end{array}$ \\
\hline 1 & Fêmea & 7000 & 5000 \\
2 & Fêmea & 8300 & 5000 \\
3 & Macho & 6700 & 3000 \\
4 & Fêmea & 4200 & 2000 \\
5 & Fêmea & 5500 & 3200 \\
6 & Macho & 2300 & 1500 \\
7 & Macho & 5700 & 2500 \\
8 & Macho & 4500 & 2000 \\
Average+ & & $5525+1749.8$ & $3025+1251.7$ \\
PatternDetour & - & & \\
\hline
\end{tabular}

The statistical analysis was done throughout the application of Student's T Test, to evaluate if the weight loose of the animals were meaningful at the end of the post-operatory observation period. The Control Group 3, constituted by 5 animals (4 male and 1 female), also with post-operatory observation period of 30 days, was utilized like a parameter to comparison in the statistical analysis (Figure 6).

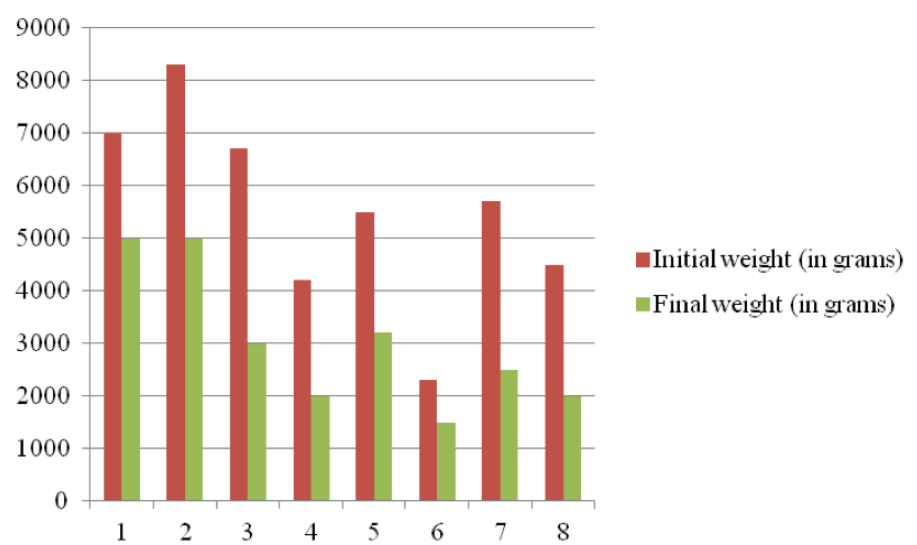

FIGURE 6 - Evaluation of the weight loose of the Test Group 3 (observation by 30 days of post-operative period).

Observing the value of the table of the Student's T Test, we can see that the $t_{0}$ of 2.43 is bigger than the $t_{c}$ of 2.20 (found value in the table with $\mathrm{p}<0.05$ and 11 degrees of liberty). Didn't exist meaningfully loose of weigh in the correspondent control group. Then, we conclude that the weight loose in the dogs submitted to the surgical technique of the "omental band" and of the group of dogs not submitted to the same technique is different and, then, we avert the null hypothesis $\left(\mathrm{H}_{0}\right)$ that affirms that there aren't differences between the weight loose of the two groups, accepting the alternative hypothesis $\left(\mathrm{H}_{1}\right)$, that affirms that the weight loose is meaningfully bigger in the group of dogs submitted to the technique of the "omental band".

\section{Histopathological analysis}

Being analyzed throughout the optic microscopy, it weren't detected meaningfully alterations in no one of the laminas, just a little inflammatory linfoplasmocitary infiltrate present between the glandules of the gastric antrum, in the region that was constricted by the "omental band" (Figures 7 and 8).

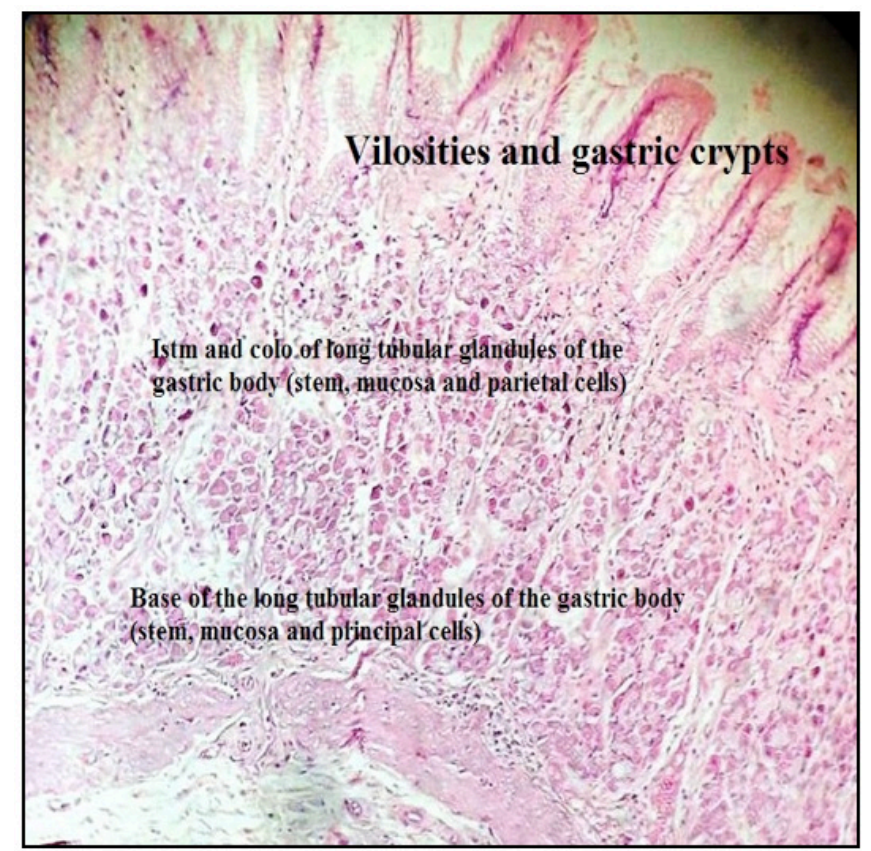

FIGURE 7 - Fragment of the gastric body (proximal to the "omental band") - optic microscopy, H\&E, increase x400.

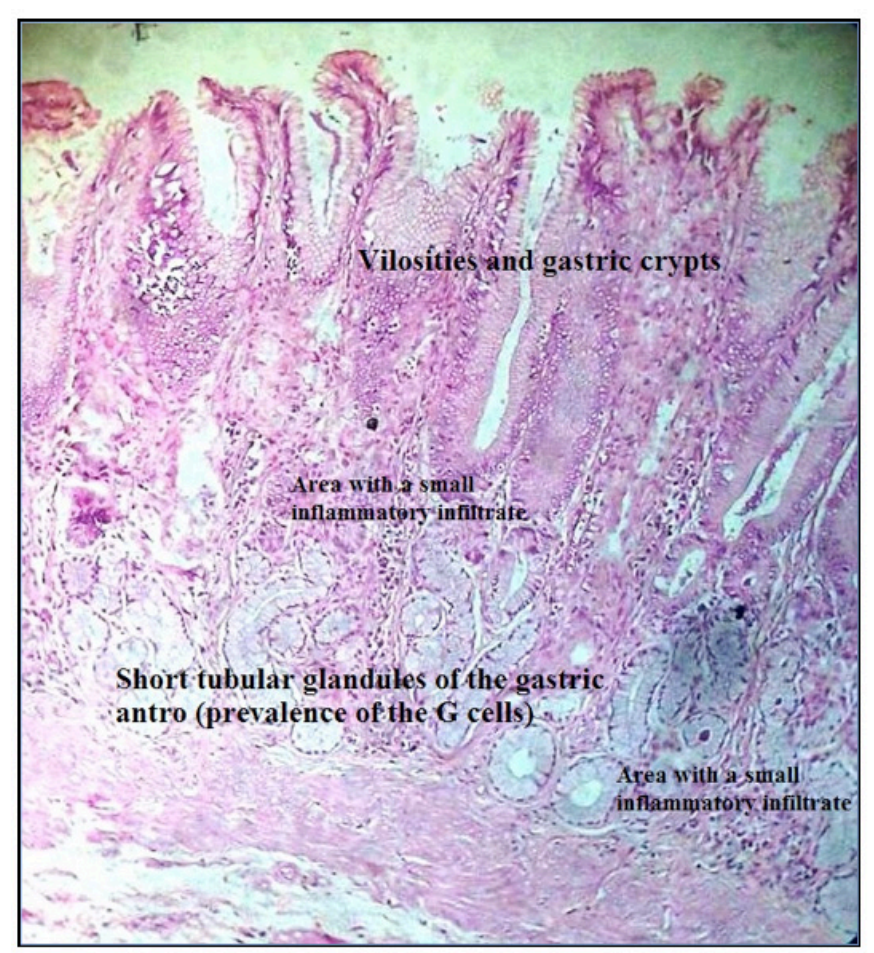

FIGURE 8 - Fragment of the gastric antrum (constricted area) - optic microscopy, H\&E, increase $x 400$. 


\section{Necropsies}

All of the dogs in this study were necropsied at the end of the post-operatory observation period. It were better studied the stomach retired of the dog number 2 of the Test Group 2 (observation by 20 days), in that was put all of the stomach out, empty and wash of the mucosa with current water. In this piece was observed the presence of the constriction promoted by the "omental band" in the gastric antrum's cavity (Figure 9) and the change of direction of the longitudinal rolls of the gastric mucosa that, in the region of the body and fund (proximal to the "omental band") were longitudinal and, in the distal region to the "omental band", became transversal (Figure 10).

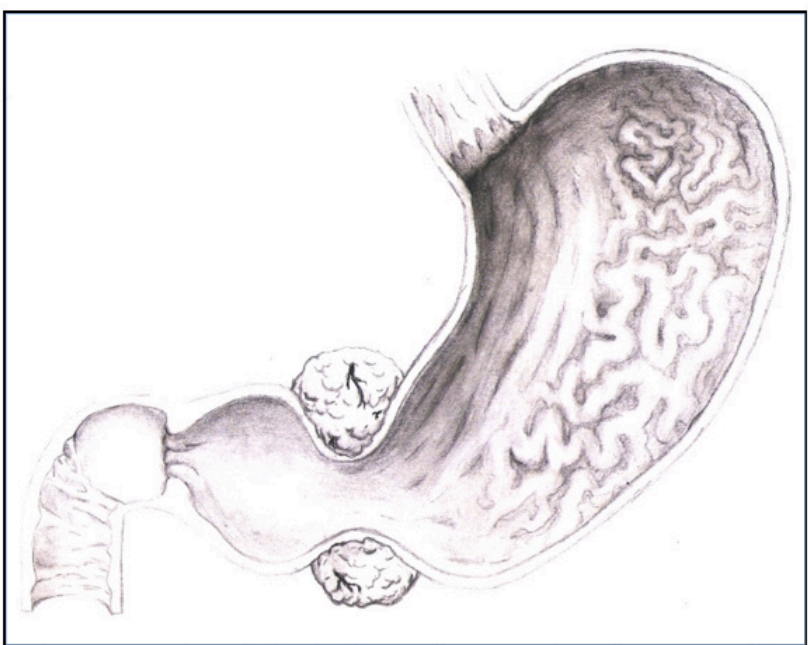

FIGURE 9 - Constriction in the gastric antrum's cavity promoted by the "omental band".

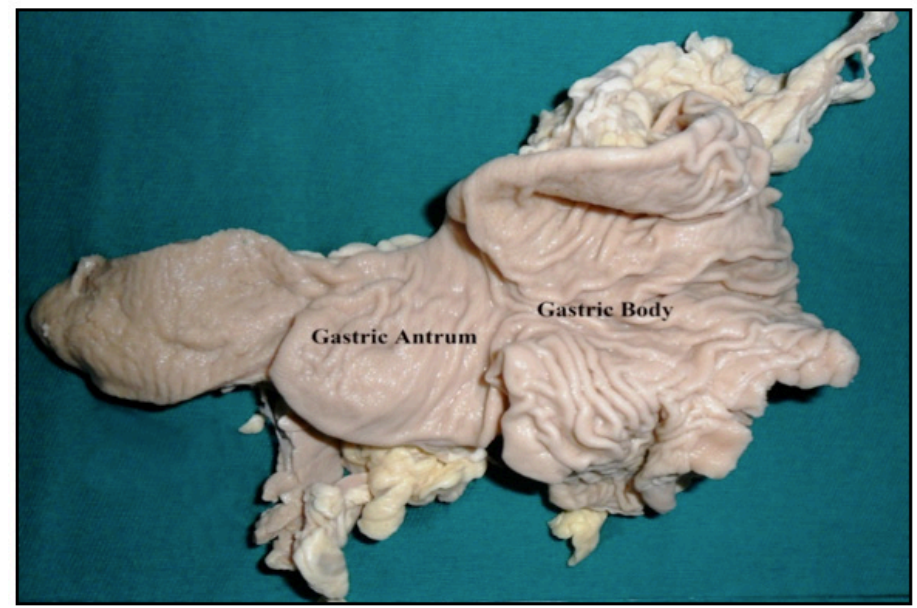

FIGURE 10 - Orientation of the gastric mucosa's rolls proximally and distally to the "omental band".

In the dog number 8 of the Test Group 3 (observation by 30 days) it was just put all the stomach out, where it was observed the presence of the "omental band" involving externally the gastric antrum (Figure 11).

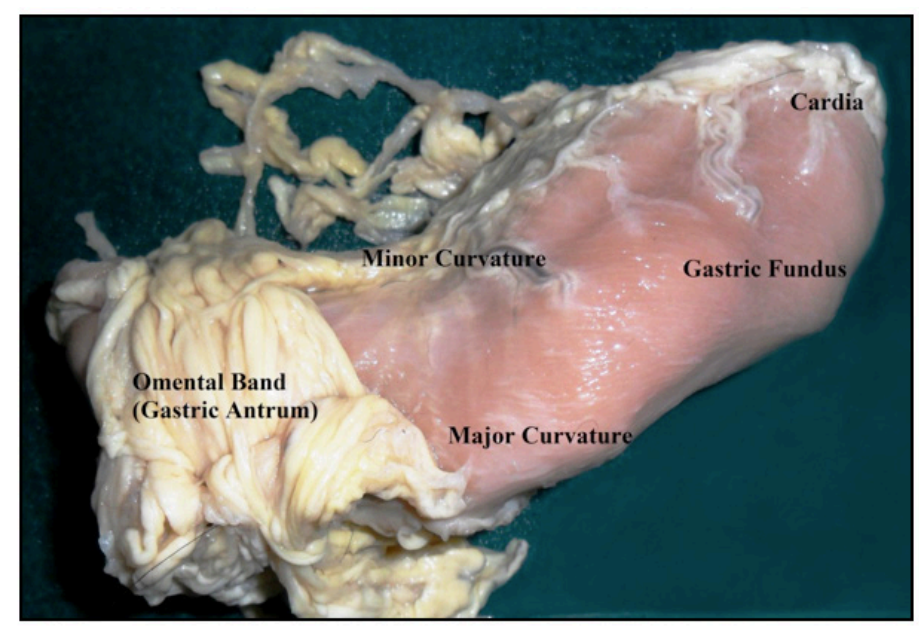

FIGURE 11 - Gastric antrum involved externally by the "omental band".

\section{Discussion}

Actually, the bariatric surgeries can be restrictive (like the gastric band), dysabsorptive (like the biliopancreatic deviation) or restrictive-dysabsorptive (like the gastric by-pass in Roux Y). In the case of the gastric bypass, there are lots of described techniques, like the gastric bypass in Roux Y, the biliopancreatic deviation, the biliopancreatic deviation with duodenal deviation and the Fobi-Capella ${ }^{2,4}$.

The basic idea of the restrictive surgeries, like the "omental band's" technique described in our study, is the reduction of the stomach's capacity to support the habitual quantity of aliments. Then, the stomach fills rapidly and the message of satiety is transmitted to the brain, doing that the person begins to ingest smaller quantities of aliments 5 .

In a general way, the surgeries that cause the diminution of the body weight present lots of advantages however are not free of complications. Combating the obesity, the benefits of the bariatric surgeries include the improvement of the quality of life, the cure of the Diabetes Mellitus II and also the diminution of the incidence of cancers that are associated with the weight excess, like the colorectal cancer and breast cancer ${ }^{6}$. In relation with the Diabetes Mellitus II's treatment, this therapeutic option diminishes the insulin's resistance and, consequently, the cardiovascular risk factors ${ }^{5}$. However, the surgical treatment of the obesity doesn't resume to the surgical act ${ }^{3}$. Like all of the high abdominal surgeries, the bariatric surgery isn't free of complications. The respiratory post-operatory complications, like atelectasis, pulmonary 
embolic, pneumonia, sleep obstructive apnea, are frequent and prolong the hospital stay of the patients, increasing the costs and the surgical morbi-mortality ${ }^{7}$. The nutritional disturbers like the protein innutrition, the iron and zinc deficiencies and the vitamin deficiencies seem to be more significant after no absorptive procedures, but also occur in the restrictive ${ }^{1}$. Between the principal reasons are: the deficient nutritional ingestion, the bad absorption in consequence of the surgical technique and the poor adherence to the vitamin reposition ${ }^{2,4,8}$. In relation to the B12 vitamin's deficiency and of the folic acid, the peripheral neuropathy is one of the most common clinical manifestations ${ }^{2,3,8}$.

Other less frequent complications, but not less important, are the intestinal obstructions that can occur in reason of the formation of hernias, Volvos or intussusceptions, rare causes of intestinal obstruction in adults, but that had its frequency elevated by the increase of the number of surgeries of this kind performed actually 9 .

Other problem presented was in relation with the Dumping syndrome, that's a consequence of the rapid empty of the substance of the stomach to the Delgado intestine. The stomach doesn't break all of the enzymes of the sugar and it ends going "brute" to the intestine. Sometimes, this mechanism is activated when big quantities of sugar are consummated or other kind of aliments. In general, the results are extremely unpleasant, can cause nausea, weakness, excessively transpiration, faint and, in some cases, diarrhea and alopecia.

In the last years it has been predominant the tendency of to associate the reduction of the gastric reservoir to its empty with a small disadvantage in the digestion throughout a gastric-jejune deviation in Roux Y. The most utilized technique was proposed by Fobi and Capella. With this procedure, the ingestion of simple carbohydrates can cause the Dumping syndrome, having an important place in the loose of weight ${ }^{10}$.

The principal objectives of the bariatric operations are the reduction of the comorbid and the increase of the life's quality in consequence of the weight loose ${ }^{10}$. The bariatric surgery is high efficacy in reduce the weight and the comorbid in obese patients. However, exists the constant pursuit for surgical techniques that represent alternatives that proportion the reach of this objectives with the smaller indices of morbid and mortality and, if possible, with the possibility of reversal of the operation ${ }^{11}$.

The "omental band's" technique, differently of the other bariatric surgeries, not utilizes hexogen materials to limit the gastric volume, reducing the possibilities of rejection or other complications in consequence of the use of these materials. By the fact of being a restrictive surgery with the involvement of the major omentum in the region of more gastric activity, there aren't also alterations in the aliments' absorption. Other advantage of the surgery is the no utilization of strong tension on the gastric wall. Because of the delicacy of the band, not occur ischemia and, then, pain. In contrary, one light compression proportionated by its involvement is sufficient to demonstrate the results presented in the analysis of the operated dogs, like the meaningfully weight loose and a rapid recovery in the post-operative period, emphasizing the minor aggression to the organism of the animals. In relation with the other bariatric surgeries, the "omental band's" technique can be considerate less invasive. However, more researches are necessary about the consequences to medium and long term of this surgical technique, to make its implementation in researches with human can be viable.

\section{Conclusion}

The "omental band's" in the gastric antrum surgical technique showed efficacy, once the weight loose proportionated to the animals submitted to this technique was meaningfully higher in comparison with the animals of the Control Group (submitted just to a median laparotomy).

\section{References}

1. Alves LFA, Gonçalves RM, Cordeiro GV, Lauria MW, Ramos AV. Beribéri pós by-pass gástrico: uma complicação não tão rara. Relato de dois casos e revisão de literatura. Arq Bras Endocrinol Metab. 2006 Jun;50(3):564-8. doi: 10.1590/S0004-27302006000300021.

2. Ayoub JAS, Alonso PA, Guimarães LMV. Efeitos da cirurgia bariátrica sobre a síndrome metabólica. Arq Bras Cir Card. 2011 Jan;24(2):140-3. doi: 10.1590/S0102-67202011000200010.

3. Bordalo LA, Teixeira TFS, Bressan J, Mourão DM. Cirurgia bariátrica: como e por que suplementar. Rev Assoc Med Bras. 2011 Jan/Fev;57(1):113-20. doi: 10.1590/S0104-42302011000100025.

4. Traina F. Deficiência de ferro no paciente submetido a ressecção gástrica ou intestinal: prevalência, causas, repercussões clínicas, abordagem diagnóstica e prevenção. Rev Bras Hematol Hemoter. 2010 Jun;32(2):78-83. doi: 10.1590/S1516-84842010005000071.

5. Marcelino LF, Patricio ZM. A complexidade da obesidade e o processo de viver após a cirurgia bariátrica: uma questão de saúde coletiva. Cienc Saúde Coletiva. 2011;16(12):4767-76. doi: 10.1590/ S1413-81232011001300025.

6. Ilias EJ, Kassab P, Malheiros CA. Câncer e obesidade: efeito da cirurgia bariátrica. Ver Assoc Med Bras. 2010 Jan;56(1):1-9. doi: 10.1590/S0104-42302010000100002.

7. Delgado PM, Lunardi AC. Complicações respiratórias pósoperatórias em cirurgia bariátrica: revisão de literatura. FisioterPesqui. 2011Out/Dec; 18 (4): 388-392. doi: 10.1590/S180929502011000400016.

8. Menezes MS, Harada KO, Alvarez G. Polineuropatia periférica dolorosa após cirurgia bariátrica: relato de dois casos. Rev Bras Anestesiol. 2008 Mai/Jun;58 (3):252-9. doi: 10.1590/S003470942008000300008 . 
9. Pereira BG, Pinheiro RP, Chain EA, Silva JLCP. Abdome agudo em gestante tratada de obesidade por cirurgia bariátrica: relato de caso. Rev Bras Ginecol Obstet. 2010 Jan/Out; 32(10):78-83. doi: 10.1590/S0100-72032010001000008.

10. Segal A, Fandino J. Indicações e contra-indicações para realização das operações bariátricas. Rev Bras Psiquiatr. 2002 Dec;24(3):6872. doi: 10.1590/S1516-44462002000700015.

11. Zilberstein B, Brito ACG, Joaquim HDG, Carballo MG. Banda gástrica com desvio jejuno-ileal: nova opção técnica em cirurgia bariátrica. Arq Bras Cir Dig. 2010 Jun;23(2): 05-7. doi: 10.1590/ S0102-67202010000200009.

\section{Acknowledgement}

To Maria Luiza Lopes Camargos, the author of the figures of the surgical technique.

\section{Correspondence:}

Sávio Lana Siqueira

Laboratório de Anatomia

Alameda Ezequiel Dias, 275/6 ${ }^{\circ}$ andar 30130-110 Belo Horizonte - MG Brasil

saviolanasiqueira@gmail.com

Received: Oct 15, 2014

Review: Dec 17, 2014

Accepted: Jan 12, 2015

Conflict of interest: none

Financial source: none

${ }^{1}$ Research performed at Human Anatomy Laboratory, Faculty of Medical Sciences of Minas Gerais(FCMMG), Belo Horizonte - MG, Brazil. 